Marquette University

e-Publications@Marquette

$1-4-2017$

\title{
Motor Timing Intraindividual Variability in Amnestic Mild Cognitive Impairment and Cognitively Intact Elders at Genetic Risk for Alzheimer's Disease
}

\author{
Christina D. Kay \\ Rosalind Franklin University of Medicine and Science \\ Michael Seidenberg \\ Rosalind Franklin University of Medicine and Science \\ Sally Durgerian \\ Medical College of Wisconsin \\ Kristy A. Nielson \\ Marquette University, kristy.nielson@marquette.edu \\ J. Carson Smith \\ University of Maryland at College Park
}

See next page for additional authors

Follow this and additional works at: https://epublications.marquette.edu/psych_fac

Part of the Psychology Commons

\section{Recommended Citation}

Kay, Christina D.; Seidenberg, Michael; Durgerian, Sally; Nielson, Kristy A.; Smith, J. Carson; Woodard, John L.; and Rao, Stephen M., "Motor Timing Intraindividual Variability in Amnestic Mild Cognitive Impairment and Cognitively Intact Elders at Genetic Risk for Alzheimer's Disease" (2017). Psychology Faculty Research and Publications. 252.

https://epublications.marquette.edu/psych_fac/252 


\section{Authors}

Christina D. Kay, Michael Seidenberg, Sally Durgerian, Kristy A. Nielson, J. Carson Smith, John L. Woodard, and Stephen M. Rao

This article is available at e-Publications@Marquette: https://epublications.marquette.edu/psych_fac/252 


\title{
Motor Timing Intraindividual Variability in Amnestic Mild Cognitive Impairment and Cognitively Intact Elders at Genetic Risk for Alzheimer's Disease
}

\author{
Christina D. Kay \\ Department of Psychology, Rosalind Franklin University of \\ Medicine and Science, \\ North Chicago, IL \\ Michael Seidenberg \\ Department of Psychology, Rosalind Franklin University of \\ Medicine and Science, \\ North Chicago, IL \\ Sally Durgerian
}

Department of Neurology and the Center for Imaging Research, Medical College of Wisconsin, Milwaukee, WI 


\author{
Kristy A. Nielson \\ Department of Neurology and the Center for Imaging Research, \\ Medical College of Wisconsin, \\ Milwaukee, WI \\ Department of Psychology, Marquette University, \\ Milwaukee, WI \\ J. Carson Smith \\ Department of Kinesiology, University of Maryland, \\ College Park, MD \\ John L. Woodard \\ Department of Psychology, Wayne State University, \\ Detroit, MI \\ Stephen M. Rao \\ 6Neurological Institute, Cleveland Clinic, \\ Cleveland, $\mathrm{OH}$
}

\begin{abstract}
Introduction: Intraindividual variability (IIV) in motor performance has been shown to predict future cognitive decline. The apolipoprotein Eepsilon 4 (APOE- $\varepsilon 4)$ allele is also a well-established risk factor for memory decline. Here, we present novel findings examining the influence of the APOE$\varepsilon 4$ allele on the performance of asymptomatic healthy elders in comparison to individuals with amnestic $\mathrm{MCl}(\mathrm{aMCl})$ on a fine motor synchronization, paced finger-tapping task (PFTT). Method: Two Alzheimer's disease (AD) risk groups, individuals with aMCl $(n=24)$ and cognitively intact APOE- $\varepsilon 4$ carriers $(n=41)$, and a control group consisting of cognitively intact APOE- $\varepsilon 4$ noncarriers $(n=65)$, completed the Rey Auditory Verbal Learning Test and the PFTT, which requires index finger tapping in synchrony with a visual stimulus (inter-stimulus interval $=333$ milliseconds). Results: Motor timing IIV, as reflected by the standard deviation of the inter-tap interval (ITI), was greater in the aMCl group relative to the two groups of cognitively intact elders; in contrast, all three groups had statistically equivalent mean ITI. No significant IIV differences were observed between the asymptomatic APOE- $\varepsilon 4$ carriers and non-carriers. Poorer episodic memory performance was associated with greater IIV, particularly in the aMCI group. Conclusions: Results suggest that increased IIV on a fine motor synchronization task is apparent in aMCl. This IIV measure was not sensitive in discriminating older asymptomatic individuals at genetic risk for AD from those without such a genetic risk. In contrast, episodic memory performance, a well-established predictor of
\end{abstract}


cognitive decline in preclinical $A D$, was able to distinguish between the two cognitively intact groups based on genetic risk.

Keywords: intraindividual variability, apolipoprotein $\varepsilon 4$, motor timing, episodic memory, aging, mild cognitive impairment

\section{Introduction}

The increased incidence of the apolipoprotein E-epsilon 4 (APOE- $\varepsilon 4)$ allele in mild cognitive impairment $(\mathrm{MCl})$ and Alzheimer's disease (AD) is well established (Caselli et al., 2007; Corder et al., 1993). There is also evidence that the presence of an APOE- $\varepsilon 4$ allele is a risk factor for conversion to $\mathrm{MCl}$ and $\mathrm{AD}$ in healthy older adults (see Small, Rosnick, Fratiglioni, \& Backman, 2004; Wisdom, Callahan, \& Hawkins, 2011 for reviews). As a result, there is considerable interest in identifying reliable cognitive markers that discriminate APOE- $\varepsilon 4$ carriers from non-carriers during the preclinical stage. Episodic memory, executive functions, and attention are the most frequent domains studied (Bondi, Salmon, Galasko, Thomas, \& Thal, 1999; Bookheimer et al., 2000; Rosen, Bergeson, Putnam, Harwell, \& Sunderland, 2002; Small et al., 2000).

These previous studies almost exclusively compared mean scores between APOE- $\varepsilon 4$ carriers and non-carriers. More recently, there has been considerable interest in the possibility that intraindividual variability (IIV) in task performance may be informative in examining cognitive functioning in older adults. Support for this notion is derived from studies showing that older adults exhibit greater fluctuations in cognitive performance and greater variability in reaction time (RT) tasks compared to younger adults (Bunce, MacDonald, \& Hultsch, 2004; Hilborn, Strauss, Hultsch, \& Hunter, 2009; Hultsch, MacDonald, \& Dixon, 2002). For example, Hultsch, MacDonald, and Dixon (2002) observed greater within-person RT variability in older adults (ages 54-94 years) compared to younger adults (ages 17-36 years) using simple, choice, and lexical and semantic decision tasks. I mportantly, these results remained even when group differences in response speed were statistically controlled.

In addition, IIV appears to predict future cognitive decline in asymptomatic elders (Bielak, Hultsch, Strauss, Macdonald, \& Hunter, 
2010a, 2010b; Lovden, Li, Shing, \& Lindenberger, 2007; MacDonald, Hultsch, \& Dixon, 2003; Sugarman et al., 2014). For example, increased IIV in simple, choice, and switching RT tasks among healthy elders was associated with a greater likelihood of being classified with greater cognitive impairment five years later (Bielak et al., 2010a). IIV in various RT tasks has also discriminated cognitively intact elders from symptomatic individuals, including those with $\mathrm{MCl}$ (Christensen et al., 2005; Dixon et al., 2007) and AD (Duchek et al., 2009; Tractenberg \& Pietrzak, 2011). RT IIV also differentiated individuals with mild $\mathrm{MCl}$ compared to moderate $\mathrm{MCl}$, and has been shown to be a better predictor of cognitive status than mean RT speed (Dixon et al., 2007).

To date, few studies have examined the relationship between estimates of IIV and the presence/absence of the APOE- $\varepsilon 4$ allele in asymptomatic elders. Duchek et al. (2009) compared group differences in healthy elders with and without the APOE- $\varepsilon 4$ allele and individuals with early stage AD on IIV measures derived from three attention tasks (Stroop, Simon, task switching). No significant differences in overall IIV measures were reported between the healthy APOE- $\varepsilon 4$ carrier and non-carrier groups, with the one exception being an IIV measure derived from Stroop incongruent trials. In a more recent study, Kalin et al. (2014) examined within- and across-domain IIV in healthy elders with and without the APOE- $\varepsilon 4$ allele, individuals with $\mathrm{MCl}$, and those diagnosed with $A D$. Measures spanning several cognitive domains, including working memory, semantic memory, and executive functioning were examined. There was no main effect across domains for IIV in healthy controls, $\mathrm{MCl}$, or AD. However, healthy elders with the APOE- $\varepsilon 4$ allele demonstrated significantly greater within-domain IIV in tasks of executive functioning compared to healthy elders without the allele, though the effect size was small ( $\eta_{p}^{2}$ $=0.035)$.

A growing body of research has demonstrated that individuals with $\mathrm{MCl}$ or early $\mathrm{AD}$ show increased variability in motor performance compared to healthy controls (Dodge, Mattek, Austin, Hayes, \& Kaye, 2012; Verghese et al., 2008). For example, using passive infrared sensors fixed on the ceiling of the homes of elderly participants, Dodge, Mattek, Austin, Hayes, and Kaye (2012) reported that 
individuals with non-amnestic $\mathrm{MCl}$ were less likely than controls to exhibit trajectories of stable walking speed variability. Longitudinal studies have also demonstrated that increased IIV in motor functioning predicts future cognitive decline in asymptomatic individuals (Bangert \& Balota, 2012; Verghese, Wang, Lipton, Holtzer, \& Xue, 2007). However, the impact of the APOE- $\varepsilon 4$ allele on motor functioning in the preclinical stage has not been previously reported.

The purpose of the current investigation was to examine the influence of the APOE- $\varepsilon 4$ allele on the performance of asymptomatic healthy elders in comparison to individuals with amnestic $\mathrm{MCl}(\mathrm{aMCl})$ on a fine motor synchronization, paced finger-tapping task (PFTT). A similar task has already been shown to discriminate individuals with early AD compared to healthy controls (Bangert \& Balota, 2012). There were three specific objectives: (1) to compare mean inter-tap interval (ITI) performance on the PFTT across three groups of elders (cognitively intact APOE- $\varepsilon 4$ non-carriers, cognitively intact APOE- $\varepsilon 4$ carriers, and individuals with aMCl); (2) to compare PFTT IIV, defined by the standard deviation of the ITI, across the three groups; (3) to examine the association of mean and IIV scores from the PFTT with scores from the Rey Auditory Verbal Learning Test (RAVLT; Rey, 1958), an episodic memory measure of list learning.

We predicted that IIV on the PFTT would distinguish between the three groups. Specifically, we predicted that the aMCl group would show greater IIV than the healthy asymptomatic groups, and the cognitively intact APOE- $\varepsilon 4$ carriers would show higher IIV than APOE$\varepsilon 4$ non-carriers. Further, we expected an inverse relationship (more variability associated with lower memory scores) between episodic memory performance on the RAVLT and IIV on the PFTT.

\section{Method}

\section{Participants}

Cognitively intact individuals ( $n=106)$ were recruited via newspaper advertisements placed in the greater Milwaukee area. Healthy participants were subsequently classified into two groups: APOE- $\varepsilon 4$ negative $(n=65)$ and APOE- $\varepsilon 4$ positive $(n=41)$. Twenty- 
four aMCl participants (9 APOE- $\varepsilon 4$ negative; 15 APOE- $\varepsilon 4$ positive) were also recruited from the Memory Disorders Clinic at the Medical College of Wisconsin (MCW). All participants completed a cognitive screening battery consisting of the Mini-Mental State Examination (MMSE; Folstein, Folstein, \& McHugh, 1975) and Mattis Dementia Rating Scale-2 (DRS-2; Jurica, Leitten, \& Mattis, 2001). The Lawton Instrumental Activities of Daily Living (IADL) Scale (Lawton \& Brody, 1969) and Geriatric Depression Scale (GDS; Yesavage et al., 1982) were also administered at study entry.

Cognitively intact participants obtained a minimum score of 27 on the MMSE and performed within 1.5 standard deviations of ageappropriate means on the DRS-2 (total score) based on normative data from the test manual (J urica et al., 2001). aMCl participants met diagnostic criteria based on Petersen's criteria (Petersen, 2004) and were evaluated by a neurologist with expertise in dementia to rule out other possible bases for the memory impairment. All aMCl participants obtained scores greater than or equal to 23 on the MMSE, scored greater than 1.5 standard deviations below age-appropriate means on the DRS-2 (total score), and below 4 on the modified Hachinski Ischemic Scale. All participants obtained a minimum score of 4 (5point scale) on the IADL scale to rule out limitations in activities of daily living, and all participants scored less than 14 on the GDS to rule out moderate to severe depressive symptoms.

Participants acknowledged no history of neurologic disease or other major medical illness and did not meet criteria for any Axis I psychiatric illness or substance abuse/dependence according to the Diagnostic and Statistical Manual of Mental Disorders, Fourth Edition (DSMIV). All participants were right-handed based on the Edinburgh Handedness I nventory (Oldfield, 1971). Informed consent was obtained in accordance with the Declaration of Helsinki and institutional guidelines established by the MCW Human Subjects Review Committee. All participants received financial compensation.

\section{Genotyping}

Genotyping for the APOE- $\varepsilon 4$ alleles $(\varepsilon 2, \varepsilon 3, \varepsilon 4)$ was determined using a polymerase chain reaction method described by Saunders et 
al. (1996) . Deoxyribonucleic acid was isolated with the Gentra Systems Autopure LS for Large Sample Nucleic Acid Purification (O'Brien, Campbell, Morken, Bair, \& Heath, 2001). The APOE- $\varepsilon 4$ negative group included participants with $\varepsilon 23(n=10)$ or $\varepsilon 33(n=55)$ genotype; the APOE- $\varepsilon 4$ positive group included participants with $\varepsilon 24$ $(n=2), \varepsilon 34(n=37)$, or $\varepsilon 44(n=2)$ genotype. The APOE genotyping distribution for MCI participants was: $\varepsilon 23(n=1), \varepsilon 33(n=8), \varepsilon 24$ ( $n$ $=1), \varepsilon 34(n=10)$ and $\varepsilon 44(n=4)$.

\section{Measures}

\section{Episodic Memory}

All participants completed the RAVLT, a commonly used episodic memory measure. The RAVLT requires individuals to learn a list of 15 words over five trials. After an interference trial, individuals complete an immediate recall trial, followed by a delayed recall trial 30 minutes later. Mean scores were analyzed for total number of words recalled across trials 1-5, immediate recall, and delayed recall.

\section{Paced Finger-Tapping Task}

All participants completed the PFTT while lying in a magnetic resonance imaging (MRI) scanner. Participants were instructed to tap a button box with their right index finger in synchrony with a visual flashing yellow and black checkerboard presented at a stimulus frequency of 3 Hertz. The PFTT was performed in a block design paradigm. Eight blocks of finger tapping alternated with periods of rest, during which participants viewed a black fixation cross in the center of a white background. Tapping blocks and periods of rest were each 12 seconds in duration. Based on the stimulus presentation frequency of 3 Hertz, a perfect synchronization score consisted of 36 finger-taps per block for a total of 288 finger-taps with a mean intertap interval (ITI) of 333 milliseconds (ms) over the course of the task. ITIs, measured in ms, were recorded using E-Prime software (Psychology Software Tools, Pittsburgh, PA). it is three standard deviations above or below each participant's individual mean ITI score were considered outliers and were removed prior to data analysis. 
NOT THE PUBLISHED VERSION; this is the author's final, peer-reviewed manuscript. The published version may be accessed by following the link in the citation at the bottom of the page.

\section{Data Analyses}

PFTT measures include mean ITI performance based on a difference score from the target synchronization ITI of $333 \mathrm{~ms}$ (M-ITI) and a measure of IIV based on the within-subject standard deviation of ITIS (SD-ITI). Initial inspection of PFTT data using quantile-quantile (QQ) plots and tests of normality (i.e., skewness and kurtosis; Shapiro-Wilk statistic) revealed that PFTT indices (M-ITI and SD-ITI) were not normally distributed. Therefore, a reciprocal square root data transformation was performed on these measures to correct for normality violations.

Group comparisons of demographics and cognitive screening measures (MMSE and DRS-2), RAVLT, and PFTT were applied using analyses of variance (ANOVAs), except for sex distribution, which was analyzed using a Pearson chi-square test. ANOVA post hoc tests include the Hochberg's GT2 and Games-Howell corrections for homogeneity and heterogeneity of variance respectively, as well as unequal sample sizes.

Preliminary data analyses between demographic variables and behavioral measures indicated significant negative correlations (range of $r=-0.18$ to -0.35 ; $p$ 's $<0.05$ ) between age and mean performance on the MMSE, RAVLT, and select DRS-2 indices. Age was also positively correlated with SD ITI on the PFTT $(r=0.17 ; p=0.05)$, and education was positively correlated with the DRS- 2 conceptualization subscale $(r=0.24 ; p=0.007)$ and DRS-2 total score $(r=0.17 ; p=$ $0.048)$.

Taking these findings into account, ANOVAs for the MMSE, DRS2 initiation/perseveration subscale, RAVLT trials 1-5, RAVLT immediate recall, RAVLT delayed recall, and SD-ITI were performed using standardized residual scores based on regression analyses with age as a predictor. ANOVAs for the DRS-2 conceptualization subscale and DRS- 2 total score were performed using standardized residual scores based on regression analyses with age and education as predictors. Partial correlations, with age as a covariate, were conducted to examine the association between RAVLT and PFTT performances across groups. 
The aMCl group consisted of 24 participants (9 APOE- $\varepsilon 4$ negative and 15 APOE- $\varepsilon 4$ positive). Preliminary t-test analyses between APOE- $\varepsilon 4$ carriers and non-carriers within the aMCl group indicated no differences in age, education, episodic memory performance, or PFTT performance ( $p$ 's $>0.05$ ). Therefore, the effect of the APOE- $\varepsilon 4$ allele was not further analyzed within the aMCl group. Rather, individuals with aMCl were considered as a distinct group of participants with substantiated cognitive status beyond a prodromal stage of impairment based on diagnostic criteria (Petersen, 2004) and results of cognitive screening measures (i.e., MMSE, DRS-2).

\section{Results}

\section{Demographics}

Group demographic statistics are shown in Table 1. There were no significant group differences in age, education, or sex distribution between groups ( $p$ 's $>0.05$ ).

\section{Cognitive Screening Battery}

Table 1 shows significant omnibus group differences in mean performance on the MMSE and DRS subscales for the three groups. As expected, post-hoc analyses revealed that aMCl participants had significantly lower scores on the MMSE and most DRS- 2 subscales ( $p$ 's $<0.05$ ), but there were no significant differences between the APOE$\varepsilon 4$ negative and positive groups ( $p$ 's $>0.05$ ) on these measures.

\section{Episodic Memory Performance}

Group comparisons of RAVLT episodic memory performance are shown in Table 1. Significant group differences emerged for all RAVLT measures with large effect sizes: trials $1-5[F(2,127)=38.24, p<$ $\left.0.001, \eta_{p}^{2}=0.376\right]$, immediate recall $[\mathrm{F}(2,127)=39.65, \mathrm{p}<0.001$, $\left.\eta_{p}^{2}=0.384\right]$, and delayed recall $\left[\mathrm{F}(2,127)=52.06, \mathrm{p}<0.001, \eta_{p}^{2}=\right.$ $0.451]$. The $\mathrm{aMCl}$ group had significantly lower performance on all three RAVLT measures compared to APOE- $\varepsilon 4$ negative and positive 
groups ( $p$ 's $<0.001$ ). In addition, post-hoc analyses revealed that the APOE- $\varepsilon 4$ positive group had significantly lower scores on RAVLT recall measures compared to the APOE- $\varepsilon 4$ negative group with medium effect sizes: immediate recall ( $p=0.007$; $d=0.63)$; delayed recall ( $p$ $=0.047 ; \mathrm{d}=0.49)$.

\section{Paced Finger-Tapping Task Performance}

Group comparisons of PFTT performance are shown in Table 1 and depicted in Figure 1. As predicted, significant group differences in IIV (SD-ITI) emerged $[F(2,127)=3.66, p=0.029, n p$

$2=0.054]$, despite equal mean level performance ( $\mathrm{M}-\mathrm{ITI})[\mathrm{F}(2,127)$

$\left.=0.93, \mathrm{p}=0.399, \eta_{p}^{2}=0.014\right]$. Post-hoc analyses revealed that $\mathrm{aMCl}$ participants had significantly greater IIV on the PFTT compared to the APOE- $\varepsilon 4$ negative group ( $p=0.030, d=0.67$ ), and a marginally significant greater IIV score compared to the APOE- $\varepsilon 4$ positive group $(p=0.069, d=0.72)$. Effects sizes are in the medium range for both comparisons, and the relatively small sample size of the APOE- $\varepsilon 4$ positive group most likely explains the attenuated group difference between the $\mathrm{MCl}$ group and the APOE- $\varepsilon 4$ positive group. However, there were no group differences in IIV between APOE- $\varepsilon 4$ negative and positive groups in post-hoc analyses ( $p=0.997, d=0.07$ ).

Nonparametric analyses using Kruskal-Wallis tests and follow-up Mann-Whitney tests (not shown) yielded similar results.

(Place Table 1 here)

(Place Figure 1 here)

\section{Correlational Analyses}

Results of partial correlational analyses (age as a covariate) between PFTT and RAVLT measures across groups are shown in Table 2. As predicted, significant negative relationships emerged between SD-ITI and all three RAVLT measures: trials $1-5(r=-0.207 ; p=0.019)$, immediate recall $(r=-0.220 ; p=0.012)$, and delayed recall $(r=-$ $0.209 ; p=0.017)$. Increased IIV was associated with lower memory scores. In contrast, PFTT mean level performance ( $\mathrm{MITI}$ ) was significantly correlated only with RAVLT immediate recall ( $r=0.205$; $p$ $=0.020)$. Partial correlations between PFTT and RAVLT measures were Francis (Routledge) and permission has been granted for this version to appear in e-Publications@Marquette. Taylor \& Francis (Routledge) does not grant permission for this article to be further copied/distributed or hosted elsewhere without the express permission from Taylor \& Francis (Routledge). 
also examined for each group separately (not shown). Within the $\mathrm{aMCl}$ group, significant negative relationships emerged between SD-ITI and RAVLT trials $1-5(r=-0.545 ; p=0.007)$ and delayed recall ( $r=-$ $0.485 ; p=0.019)$. Increased variability was associated with lower memory scores. In contrast, no significant correlations emerged between PFTT and RAVLT measures for the APOE- $\varepsilon 4$ positive or APOEع4 negative groups.

(Place Table 2 here)

\section{Discussion}

The purpose of this study was to examine the performance of healthy elders with and without the APOE- $\varepsilon 4$ allele and an aMCI group on a measure of motor performance, the PFTT. We were particularly interested in the potential differences on a measure of IIV in distinguishing between the three groups. In the context of similar mean ITI accuracy across groups, we found motor timing IIV to be greater for the aMCl group compared to both groups of cognitively intact elders. However, we found no significant group differences between asymptomatic APOE- $\varepsilon 4$ non-carriers and carriers in motor timing ITI mean accuracy or IIV. We also found that poorer performance on RAVLT indices was associated with higher IIV, particularly in the aMCl group.

As expected, the aMCl group demonstrated significantly poorer neuropsychological test performance compared to cognitively intact groups (APOE- $\varepsilon 4$ carriers and non-carriers) on all RAVLT measures (Petersen et al., 1999). We also found that cognitively intact APOE- $\varepsilon 4$ carriers had significantly poorer performance on RAVLT indices than non-carriers, consistent with research showing poorer episodic memory performance during this clinically asymptomatic stage (El Haj et al., 2016; Twamley, Ropacki, \& Bondi, 2006).

The results reported here are consistent with several recent studies showing that increased IIV in performance on a variety of fine and gross motor tasks (i.e., finger tapping, walking speed, etc.) may constitute a useful cognitive marker for the transition from cognitively intact to the prodromal aMCl stage (Buracchio, Dodge, Howieson, 
Wasserman, \& Kaye, 2010; Dodge et al., 2012; Verghese et al., 2007). Further, these findings emerged in the context of equivalent mean level motor timing performance across groups, which suggests that IIV indices may provide valuable information above and beyond traditional measures of cognitive performance based on mean scores (Hultsch, MacDonald, Hunter, Levy-Bencheton, \& Strauss, 2000). Reliance on the standard approach of comparing mean level performance between groups would not have detected differences in motor timing variability at the prodromal $\mathrm{aMCl}$ stage in our sample.

Post-hoc analyses revealed that aMCl participants had significantly greater IIV on the PFTT compared to APOE- $\varepsilon 4$ non-carriers and a marginally significant greater IIV score compared to APOE- $\varepsilon 4$ carriers; however, effect sizes are in the medium range for both comparisons with a slightly stronger effect for the latter comparison. The relatively small sample size of the APOE- $\varepsilon 4$ positive group most likely explains this attenuated group difference.

Consistent with previous studies, we found no significant differences in performance variability on the PFTT between cognitively intact APOE- $\varepsilon 4$ carriers and non-carriers. Duchek et al. (2009) also did not find significant differences in IIV between healthy APOE- $\varepsilon 4$ carriers and non-carriers using three different selective attention tasks, except for a single score on incongruent trials of the Stroop task. Kalin et al. (2014) reported a very small effect size difference between healthy elders with the APOE- $\varepsilon 4$ allele compared to those without the allele for within-domain IIV in tasks of executive functioning. Nevertheless, longitudinal data is necessary to more clearly determine the predictive value of IIV for progression to the $\mathrm{MCl}$ stage and dementia.

It is important to note that, while the aMCl group exhibited significantly greater motor timing IIV compared to cognitively intact elders, the magnitude of this difference was relatively small compared to the large effect sizes that emerged for the same group comparisons of episodic memory performances. Further, in contrast with episodic memory performance, which was able to distinguish between healthy APOE- $\varepsilon 4$ carriers and non-carriers, IIV on the PFTT was equal for both groups of cognitively intact elders. This suggests that episodic memory performance, in comparison to motor timing IIV, continues to serve as 
the most reliable predictor of cognitive decline during the asymptomatic preclinical stage of AD.

Age-related differences in IIV may be most apparent on speeded tasks that place increased demands on executive functioning or working memory (Dixon et al., 2007), or other cognitively complex tasks (Hultsch et al., 2000; Strauss, Bielak, Bunce, Hunter, \& Hultsch, 2007). It is possible that IIV on the PFTT did not recruit sufficiently complex executive function and attentional control mechanisms to elicit strong IIV differences between cognitively intact APOE- $\varepsilon 4$ carriers and non-carriers. For example, it may be necessary to employ tasks that have stronger working memory demands. In contrast, $\mathrm{MCl}$ is characterized by attentional lapses, failures of inhibition, and reduced executive control, all of which can serve as mechanisms for increased IIV.

Viewed from a neurological perspective, there may be particular brain regions that are important in maintaining low response variability. Recent neuroimaging studies indicate that increased IIV is associated with neurophysiological deterioration within frontal systems, particularly in white matter. For example, Bunce et al. (2007) found that white matter hyperintensities were significantly correlated with IIV on speeded cognitive tasks in healthy older adults (ages 6064). Importantly, this relationship was unique to white matter integrity in the frontal lobes, demonstrating that these neural pathways play a key role in increased IIV. Functional MRI studies have also shown important relationships between the frontal lobes and increased IIV (Bellgrove, Hester, \& Garavan, 2004). Further, alterations in select neurotransmitters, such as neuromodulatory deficiencies in dopamine, may underscore increased IIV in cognitive performance (Hultsch et al., 2002; Li, Lindenberger, \& Sikstrom, 2001; Rabbitt, Osman, Moore, \& Stollery, 2001). While subtle alterations within frontal systems may be detectable via imaging techniques, our results suggest that these changes are not yet apparent through behavioral measures of IIV in either APOE- $\varepsilon 4$ carrier or non-carrier asymptomatic individuals.

There are limitations that may have obscured the potential IIV differences in comparison of the APOE- $\varepsilon 4$ carriers and non-carriers prior to symptom onset. First, we employed only a single measure of 
motor timing IIV (fine motor synchronization) to an external stimulus. Additional measures of motor timing and other indices of motor movement may provide a more nuanced assessment of motor variability. A broad motor performance battery including fine, gross, and complex tasks, in addition to measures of gait and ambulation, may prove useful in eliciting differences in asymptomatic elders with different genetic risk factors.

Further, the PFTT may not have recruited sufficient cognitive complexity to distinguish between APOE- $\varepsilon 4$ carriers and non-carriers. Assuming IIV is a frontally mediated process, as has been suggested (i.e., Bellgrove et al., 2004), then more complex executive tasks may prove better able to distinguish those at risk for AD. Specifically, tasks that tap aspects of attentional selection, inhibition, and switching may be considered for future studies, as such tasks appear to be particularly sensitive to $\mathrm{MCl}$ and early AD (Castel, Balota, Hutchison, Logan, \& Yap, 2007; Spieler, Balota, \& Faust, 1996).

Ultimately, a longitudinal design is necessary to provide more definitive statements about the predictive utility of increased IIV in individuals with genetic susceptibility to AD. With regard to sampling procedures, cognitively intact study participants were volunteers living independently in the local community and were highly educated, mostly Caucasian (98.5\%), and predominantly female $(70.5 \%)$. These factors limit the generalizability of our findings, and future investigations would benefit from inclusion of a more heterogeneous sample.

\section{Conclusions}

Overall, findings from this study suggest that increased IIV on a fine motor synchronization task is evident at the aMCl stage, but IIV differences did not distinguish between APOE- $\varepsilon 4$ allele carriers and non-carriers during the preclinical stage. Further, motor timing IIV appears to have weaker capacity to distinguish between individuals at $A D$ risk compared to episodic memory performance, a well-established predictor of cognitive decline. More definitive findings from longitudinal studies and the investigation of a broader repertoire of motor functions 
are needed to determine the value of IIV measurement in predicting cognitive decline in asymptomatic elders.

\section{Acknowledgements}

This project was supported by NIH grant, R01 AG022304, awarded to SMR. The content is solely the responsibility of the authors and does not necessarily represent the official views of the National Institute on Aging or the National Institutes of Health. The information in this manuscript has never been published either electronically or in print. The authors report no conflicts of interest. The authors would like to thank Steven Miller, Ph.D. for assistance with statistical analyses, Patrick R. Kay for assistance with data configuration, and Melissa A. Lancaster, Ph.D., Monica A. Matthews, Cassandra C. Kandah, Christina M. Figueroa, Kathleen E. Hazlett, Michael A. Sugarman, and Andria L. Norman for helpful comments.

\section{References}

Bangert, A. S., \& Balota, D. A. (2012). Keep Up the Pace: Declines in Simple Repetitive Timing Differentiate Healthy Aging from the Earliest Stages of Alzheimer's Disease. Journal of the International Neuropsychological Society, 1-12. doi:S1355617712000860

Bellgrove, M. A., Hester, R., \& Garavan, H. (2004). The functional neuroanatomical correlates of response variability: evidence from a response inhibition task. Neuropsychologia, 42(14), 1910-1916. doi: 10.1016/j.neuropsychologia.2004.05.007

Bielak, A. A., Hultsch, D. F., Strauss, E., Macdonald, S. W., \& Hunter, M. A. (2010a). Intraindividual variability in reaction time predicts cognitive outcomes 5 years later. Neuropsychology, 24(6), 731-741. doi: $10.1037 / a 0019802$

Bielak, A. A., Hultsch, D. F., Strauss, E., MacDonald, S. W., \& Hunter, M. A. (2010b). Intraindividual variability is related to cognitive change in older adults: evidence for within-person coupling. Psychology and Aging, 25(3), 575-586. doi: 10.1037/a0019503

Bondi, M. W., Salmon, D. P., Galasko, D., Thomas, R. G., \& Thal, L. J. (1999). Neuropsychological function and apolipoprotein $\mathrm{E}$ genotype in the preclinical detection of Alzheimer's disease. Psychology and Aging, 14(2), 295-303.

Bookheimer, S. Y., Strojwas, M. H., Cohen, M. S., Saunders, A. M., PericakVance, M. A., Mazziotta, J. C., \& Small, G. W. (2000). Patterns of brain 
activation in people at risk for Alzheimer's disease. New England J ournal of Medicine, 343(7), 450-456. doi: 10.1056/NEJ M200008173430701

Bunce, D., Anstey, K. J., Christensen, H., Dear, K., Wen, W., \& Sachdev, P. (2007). White matter hyperintensities and within-person variability in community-dwelling adults aged 60-64 years. Neuropsychologia, 45(9), 2009-2015. doi:10.1016/j.neuropsychologia.2007.02.006

Bunce, D., MacDonald, S. W., \& Hultsch, D. F. (2004). Inconsistency in serial choice decision and motor reaction times dissociate in younger and older adults. Brain and Cognition, 56(3), 320-327. doi: 10.1016/j.bandc.2004.08.006

Buracchio, T., Dodge, H. H., Howieson, D., Wasserman, D., \& Kaye, J. (2010). The trajectory of gait speed preceding mild cognitive impairment. Archives of Neurology, 67(8), 980-986. doi: 10.1001/archneurol.2010.159

Caselli, R. J., Reiman, E. M., Locke, D. E., Hutton, M. L., Hentz, J. G., Hoffman-Snyder, C., . . Osborne, D. (2007). Cognitive domain decline in healthy apolipoprotein E epsilon4 homozygotes before the diagnosis of mild cognitive impairment. Archives of Neurology, 64(9), 1306-1311. doi: 10.1001/archneur.64.9.1306

Castel, A. D., Balota, D. A., Hutchison, K. A., Logan, J. M., \& Yap, M. J . (2007). Spatial attention and response control in healthy younger and older adults and individuals with Alzheimer's disease: evidence for disproportionate selection impairments in the Simon task. Neuropsychology, 21(2), 170-182. doi: 10.1037/0894-4105.21.2.170

Christensen, H., Dear, K. B., Anstey, K. J., Parslow, R. A., Sachdev, P., \& Jorm, A. F. (2005). Within-occasion intraindividual variability and preclinical diagnostic status: is intraindividual variability an indicator of mild cognitive impairment? Neuropsychology, 19(3), 309-317. doi: 10.1037/0894-4105.19.3.309

Corder, E. H., Saunders, A. M., Strittmatter, W. J., Schmechel, D. E., Gaskell, P. C., Small, G. W., . . . Pericak-Vance, M. A. (1993). Gene dose of apolipoprotein $\mathrm{E}$ type 4 allele and the risk of Alzheimer's disease in late onset families. Science, 261(5123), 921-923.

Dixon, R. A., Garrett, D. D., Lentz, T. L., MacDonald, S. W., Strauss, E., \& Hultsch, D. F. (2007). Neurocognitive markers of cognitive impairment: exploring the roles of speed and inconsistency. Neuropsychology, 21(3), 381-399. doi:10.1037/0894-4105.21.3.381

Dodge, H. H., Mattek, N. C., Austin, D., Hayes, T. L., \& Kaye, J. A. (2012). Inhome walking speeds and variability trajectories associated with mild cognitive impairment. Neurology, 78(24), 1946-1952. doi: 10.1212/WNL.0b013e318259e1de Francis (Routledge) and permission has been granted for this version to appear in e-Publications@Marquette. Taylor \& Francis (Routledge) does not grant permission for this article to be further copied/distributed or hosted elsewhere without the express permission from Taylor \& Francis (Routledge). 
Duchek, J. M., Balota, D. A., Tse, C. S., Holtzman, D. M., Fagan, A. M., \& Goate, A. M. (2009). The utility of intraindividual variability in selective attention tasks as an early marker for Alzheimer's disease. Neuropsychology, 23(6), 746-758. doi: 10.1037/a0016583

El Haj, M., Antoine, P., Amouyel, P., Lambert, J. C., Pasquier, F., \& Kapogiannis, D. (2016). Apolipoprotein E (APOE) epsilon4 and episodic memory decline in Alzheimer's disease: A review. Ageing Research Reviews, 27, 15-22. doi:10.1016/j.arr.2016.02.002

Folstein, M. F., Folstein, S. E., \& McHugh, P. R. (1975). "Mini-mental state". A practical method for grading the cognitive state of patients for the clinician. Journal of Psychiatric Research, 12(3), 189-198.

Hilborn, J. V., Strauss, E., Hultsch, D. F., \& Hunter, M. A. (2009). Intraindividual variability across cognitive domains: investigation of dispersion levels and performance profiles in older adults. Journal of Clinical and Experimental Neuropsychology, 31(4), 412-424. doi: $10.1080 / 13803390802232659$

Hultsch, D. F., MacDonald, S. W., \& Dixon, R. A. (2002). Variability in reaction time performance of younger and older adults. Journals of Gerontology. Series B: Psychological Sciences and Social Sciences, 57(2), P101-115.

Hultsch, D. F., MacDonald, S. W., Hunter, M. A., Levy-Bencheton, J., \& Strauss, E. (2000). Intraindividual variability in cognitive performance in older adults: comparison of adults with mild dementia, adults with arthritis, and healthy adults. Neuropsychology, 14(4), 588-598.

Jurica, P., Leitten, C., \& Mattis, S. (2001). Dementia Rating Scale-2 (DRS-2). Odessa, FL: Psychological Assessment Resources.

Kalin, A. M., Pfluger, M., Gietl, A. F., Riese, F., Jancke, L., Nitsch, R. M., \& Hock, C. (2014). Intraindividual variability across cognitive tasks as a potential marker for prodromal Alzheimer's disease. Frontiers in Aging Neuroscience, 6, 147. doi: 10.3389/fnagi.2014.00147

Lawton, M. P., \& Brody, E. M. (1969). Assessment of older people: selfmaintaining and instrumental activities of daily living. Gerontologist, 9(3), 179-186.

Li, S. C., Lindenberger, U., \& Sikstrom, S. (2001). Aging cognition: from neuromodulation to representation. Trends in Cognitive Sciences, 5(11), 479-486.

Lovden, M., Li, S. C., Shing, Y. L., \& Lindenberger, U. (2007). Within-person trial-to-trial variability precedes and predicts cognitive decline in old and very old age: longitudinal data from the Berlin Aging Study. Neuropsychologia, 45(12), 2827-2838. doi: 10.1016/j.neuropsychologia.2007.05.005

MacDonald, S. W., Hultsch, D. F., \& Dixon, R. A. (2003). Performance variability is related to change in cognition: evidence from the Victoria 
Longitudinal Study. Psychology and Aging, 18(3), 510-523.

doi: 10.1037/0882-7974.18.3.510

O'Brien, D. P., Campbell, K. A., Morken, N. W., Bair, R. J., \& Heath, E. M. (2001). Automated nucleic acid purification for large samples. Journal of the Association for Laboratory Automation, 6(2), 67-70. doi: 10.1016/S1535-5535(04)00131-5

Oldfield, R. C. (1971). The assessment and analysis of handedness: the Edinburgh inventory. Neuropsychologia, 9(1), 97-113.

Petersen, R. C. (2004). Mild cognitive impairment as a diagnostic entity. J ournal of Internal Medicine, 256(3), 183-194. doi:10.1111/j.13652796.2004.01388.x

Petersen, R. C., Smith, G. E., Waring, S. C., Ivnik, R. J., Tangalos, E. G., \& Kokmen, E. (1999). Mild cognitive impairment: clinical characterization and outcome. Archives of Neurology, 56(3), 303-308.

Rabbitt, P., Osman, P., Moore, B., \& Stollery, B. (2001). There are stable individual differences in performance variability, both from moment to moment and from day to day. Quarterly J ournal of Experimental Psychology. A: Human Experimental Psychology, 54(4), 981- 1003. doi: $10.1080 / 713756013$

Rey, A. (1958). L'examen clinique en psychologie ([1. éd.] ed.). Paris: Presses universitaires de France.

Rosen, V. M., Bergeson, J. L., Putnam, K., Harwell, A., \& Sunderland, T. (2002). Working memory and apolipoprotein E: what's the connection? Neuropsychologia, 40(13), 2226-2233.

Saunders, A. M., Hulette, O., Welsh-Bohmer, K. A., Schmechel, D. E., Crain, B., Burke, J. R., . . . Rosenberg, C. (1996). Specificity, sensitivity, and predictive value of apolipoprotein-E genotyping for sporadic Alzheimer's disease. Lancet, 348(9020), 90-93.

Small, B. J., Graves, A. B., McEvoy, C. L., Crawford, F. C., Mullan, M., \& Mortimer, J. A. (2000). Is APOE--epsilon4 a risk factor for cognitive impairment in normal aging? Neurology, 54(11), 2082-2088.

Small, B. J., Rosnick, C. B., Fratiglioni, L., \& Backman, L. (2004). Apolipoprotein $\mathrm{E}$ and cognitive performance: a meta-analysis. Psychology and Aging, 19(4), 592-600. doi:10.1037/08827974.19.4.592

Spieler, D. H., Balota, D. A., \& Faust, M. E. (1996). Stroop performance in healthy younger and older adults and in individuals with dementia of the Alzheimer's type. J ournal of Experimental Psychology: Human Perception and Performance, 22(2), 461-479.

Strauss, E., Bielak, A. A., Bunce, D., Hunter, M. A., \& Hultsch, D. F. (2007). Within-person variability in response speed as an indicator of cognitive impairment in older adults. Neuropsychology, Development, and 
Cognition. Section B: Aging, Neuropsychology and Cognition, 14(6), 608-630. doi: 10.1080/13825580600932419

Sugarman, M. A., Woodard, J. L., Nielson, K. A., Smith, J. C., Seidenberg, M., Durgerian, S., . . . Rao, S. M. (2014). Performance variability during a multitrial list-learning task as a predictor of future cognitive decline in healthy elders. Journal of Clinical and Experimental Neuropsychology, 36(3), 236-243. doi: 10.1080/13803395.2013.877875

Tractenberg, R. E., \& Pietrzak, R. H. (2011). Intra-individual variability in Alzheimer's disease and cognitive aging: definitions, context, and effect sizes. PloS One, 6(4), e16973. doi: 10.1371/journal.pone.0016973

Twamley, E. W., Ropacki, S. A., \& Bondi, M. W. (2006). Neuropsychological and neuroimaging changes in preclinical Alzheimer's disease. Journal of the International Neuropsychological Society, 12(5), 707-735.

Verghese, J., Robbins, M., Holtzer, R., Zimmerman, M., Wang, C., Xue, X., \& Lipton, R. B. (2008). Gait dysfunction in mild cognitive impairment syndromes. J ournal of the American Geriatrics Society, 56(7), 12441251. doi: 10.1111/j.1532-5415.2008.01758.x

Verghese, J., Wang, C., Lipton, R. B., Holtzer, R., \& Xue, X. (2007). Quantitative gait dysfunction and risk of cognitive decline and dementia. J ournal of Neurology, Neurosurgery and Psychiatry, 78(9), 929-935. doi: 10.1136/jnnp.2006.106914

Wisdom, N. M., Callahan, J. L., \& Hawkins, K. A. (2011). The effects of apolipoprotein $\mathrm{E}$ on non-impaired cognitive functioning: a metaanalysis. Neurobiology of Aging, 32(1), 63-74. doi: 10.1016/j.neurobiolaging.2009.02.003

Yesavage, J. A., Brink, T. L., Rose, T. L., Lum, O., Huang, V., Adey, M., \& Leirer, V. O. (1982). Development and validation of a geriatric depression screening scale: a preliminary report. Journal of Psychiatric Research, 17(1), 37-49. 
NOT THE PUBLISHED VERSION; this is the author's final, peer-reviewed manuscript. The published version may be accessed by following the link in the citation at the bottom of the page.

Table 1. Demographics and Cognitive Screening, Episodic Memory, and Paced Finger-Tapping Performances by Group

\begin{tabular}{|c|c|c|c|c|c|c|c|c|c|c|}
\hline & \multicolumn{2}{|c|}{$\varepsilon 4-(n=65)$} & \multicolumn{2}{|c|}{$\varepsilon 4+(n=41)$} & \multicolumn{2}{|c|}{$\mathrm{MCI}^{\wedge}(n=24)$} & \multirow[b]{2}{*}{$F$} & \multirow[b]{2}{*}{$p$} & \multirow[b]{2}{*}{$\eta_{p}{ }^{2}$} & \multirow[b]{2}{*}{$(p ' s<.05)$} \\
\hline & Mean & $S D$ & Mean & $S D$ & Mean & $S D$ & & & & \\
\hline \multicolumn{11}{|l|}{ Demographics } \\
\hline Age (years) & 73.3 & 5.1 & 72.2 & 4.9 & 75.5 & 6.6 & 3.01 & .053 & .045 & \\
\hline Education (years) & 14.5 & 2.4 & 15.6 & 2.8 & 14.4 & 2.7 & 2.56 & .081 & .039 & \\
\hline Sex (male/female) & $19 / 46$ & & $14 / 27$ & & $6 / 18$ & & $0.64^{\mathrm{a}}$ & .726 & $.070^{\mathrm{b}}$ & \\
\hline \multicolumn{11}{|l|}{ Cognitive Screening } \\
\hline $\operatorname{MMSE}(/ 30)$ & 29.3 & 0.8 & 29.1 & 1.1 & 27.3 & 2.1 & $22.66^{\mathrm{c}}$ & $<.001$ & .263 & $\mathrm{MCI}<\varepsilon 4-, \varepsilon 4+$ \\
\hline \multicolumn{11}{|l|}{ DRS-2 } \\
\hline Attention (/37) & 36.5 & 0.7 & 36.4 & 0.8 & 35.6 & 1.5 & 7.84 & .001 & .110 & $\mathrm{MCI}<\varepsilon 4-$ \\
\hline Initiation/Perseveration ( $/ 37)$ & 36.8 & 0.5 & 36.5 & 1.8 & 34.3 & 2.7 & $20.44^{c}$ & $<.001$ & .243 & $\mathrm{MCI}<\varepsilon 4-, \varepsilon 4+$ \\
\hline Construction (/6) & 5.9 & 0.2 & 6.0 & 0.2 & 5.8 & 0.4 & 3.97 & .021 & .059 & ns \\
\hline Conceptualization (/39) & 37.2 & 2.5 & 37.3 & 1.8 & 36.1 & 2.3 & $1.36^{d}$ & .261 & .021 & \\
\hline Memory $(/ 25)$ & 24.1 & 1.1 & 24.1 & 1.4 & 19.4 & 4.1 & 50.82 & $<.001$ & .445 & $\mathrm{MCI}<\varepsilon 4-, \varepsilon 4+$ \\
\hline Total $(/ 144)$ & 140.5 & 2.9 & 140.0 & 3.7 & 131.2 & 7.0 & $42.70^{d}$ & $<.001$ & .402 & $\mathrm{MCI}<\varepsilon 4-, \varepsilon 4+$ \\
\hline \multicolumn{11}{|l|}{ Episodic Memory } \\
\hline \multicolumn{11}{|l|}{ RAVLT } \\
\hline Trials $1-5(/ 75)$ & 48.6 & 8.8 & 46.2 & 8.8 & 29.8 & 7.7 & $38.24^{c}$ & $<.001$ & .376 & $\mathrm{MCI}<\varepsilon 4-, \varepsilon 4+$ \\
\hline Immediate Recall ( /15) & 9.8 & 2.6 & 8.4 & 2.5 & 4.1 & 2.5 & $39.65^{\mathrm{c}}$ & $<.001$ & .384 & $\mathrm{MCI}<\varepsilon 4-, \varepsilon 4+; \varepsilon 4+<\varepsilon 4-$ \\
\hline Delayed Recall (/15) & 9.8 & 2.7 & 8.7 & 3.0 & 3.0 & 1.9 & $52.06^{\mathrm{c}}$ & $<.001$ & .451 & $\mathrm{MCI}<\varepsilon 4-, \varepsilon 4+; \varepsilon 4+<\varepsilon 4-$ \\
\hline \multicolumn{11}{|l|}{ Paced Finger-Tapping (ms) } \\
\hline M-ITI (mean ${ }_{x}$ - target) & -21 & 66 & -35 & 52 & -71 & 88 & $0.93^{e}$ & .399 & .014 & \\
\hline SD-ITI & 55 & 31 & 53 & 30 & 82 & 48 & $3.66^{\mathrm{ce}}$ & .029 & .054 & $\mathrm{MCI}>\varepsilon 4-, \varepsilon 4+^{*}$ \\
\hline
\end{tabular}

Note. $\varepsilon 4=$ apolipoprotein E-epsilon $4 ; \mathrm{MCl}=$ mild cognitive impairment; MMSE = Mini-Mental State Examination; DRS-2 = Dementia Rating Scale-2nd Edition; RAVLT = Rey Auditory Verbal Learning Test; $\mathrm{ms}=$ milliseconds; $\mathrm{ITI}=$ inter-tap interval. ^9 $14-, 15 \varepsilon 4+$. ${ }^{\text {aPearson }}$ Chi-Square Test. ${ }^{b}$ Cramer's V . 'ANOVA results using standardized residual scores based on regression with age as a predictor. ${ }^{\mathrm{d}}$ ANOVA results using standardized residual scores based on regression with age and education as predictors.

Table 2. Pearson Correlations ${ }^{a}$ between Paced Finger-Tapping and Episodic Memory Test Performances across Groups

\begin{tabular}{lcc} 
& $M-I T I$ & $S D-I T I$ \\
\hline RAVLT & & \\
Trials 1-5 & .156 & $-.207^{*}$ \\
Immediate Recall & $.205^{*}$ & $-.220^{*}$ \\
Delayed Recall & .138 & $-.209^{*}$
\end{tabular}

Note. RAVLT = Rey Auditory Verbal Learning Test; M-ITI = mean inter-tap interval; SD-ITI = standard deviation of inter-tap interval. apartial correlations (covariate: age). * $\mathrm{p}<.05$. 
NOT THE PUBLISHED VERSION; this is the author's final, peer-reviewed manuscript. The published version may be accessed by following the link in the citation at the bottom of the page.

\section{Figure Legend}

Figure 1. Paced finger-tapping performance by group. Left panel presents mean accuracy, represented by mean inter-tap interval (ITI) minus the target ITI (333 milliseconds). Right panel presents mean standard deviation of the ITI, a measure of intraindividual variability. Error bars represent standard error of the mean. $\varepsilon 4=$ apolipoprotein E-epsilon $4 ; \mathrm{MCl}=$ mild cognitive impairment; ITI = inter-tap interval.

$* \mathrm{p}<.05$.

Mean Difference ITI

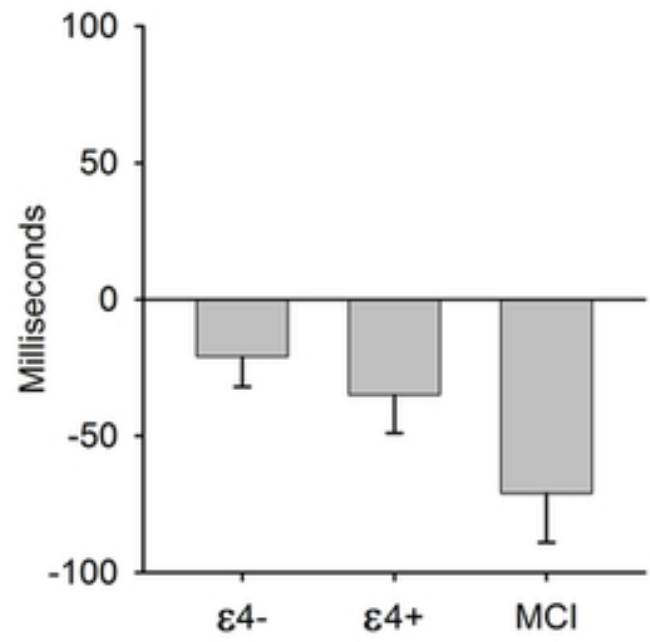

Standard Deviation ITI

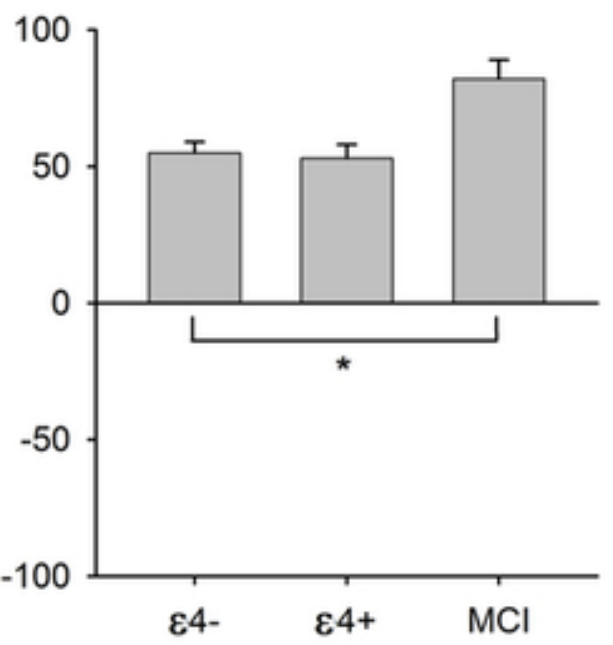

